\title{
EL DIAGNOSTICO DE LA TUBERCULOSIS PULMONAR POR CULTIVO DE ESPUTO EN UNIDADES DE SALUD CON RECURSOS MINIMOS
}

\author{
LUIS CARLOS OROZCO VARGAS*, CLARA INES LEON**, MAYE BERNAL RIVERA***
}

\section{INTRODUCCION}

En trabajos anteriores ${ }^{(1,2)}$ hemos demostrado claramente que el método del escobillón de Kudoh para cultivo de esputo, con modificaciones realizadas por nosotros, simplifica el diagnóstico de la tuberculosis pulmonar. También hemos demostrado que la viabilidad del $\boldsymbol{M}$. tuberculosis no se altera, si se expone hasta por 48 horas a fosfato trisódico (FTS) al $4.3 \%{ }^{(3)}$.

Pensando en la posibilidad de ampliar la cobertura del diagnóstico bacteriológico de la tuberculosis pulmonar por cultivo de esputo, realizamos un trabajo que produjera una situación similar a la de algunos centros de salud-donde no existe el recurso de incubadora microbiológica.

\section{MATERIALES Y METODOS}

Se procesaron 75 esputos de sintomáticos respiratorios dentro de un esquema similar al descrito previamente en nuestro artículo sobre vitalidad del $M$. tuberculosis expuesto al FTS ${ }^{(3)}$ con pequeñas modificaciones, que describiremos a continuación (ver esquema $1)$.

A cada esputo A se le practicó baciloscopia (Bx); el esputo restante se mezcló con una cantidad igual de FTS al 4.3\% (10 g Na3PO4. $12 \mathrm{H} 20$ en $100 \mathrm{ml}$. de A.D.) y una vez homogenizado se dividió en tres alícuotas, las cuales fueron sembradas por el método del escobillón ${ }^{(1)}, 1.24$ y 48 horas después de realizada la mezcla en cuatro tubos con medio de Ogawa, modificado por Kudoh (O-K).
Después de sembrados los tubos, dos se incubaron inmediatamente a $37^{\circ} \mathrm{C}$., y los otros dos se dejaron a temperatura ambiente $\left(18-25^{\circ} \mathrm{C}\right.$.) durante dos semanas.

Las lecturas de los cultivos se hicieron la primera y segunda semana y luego en forma bisemanal hasta la 12a semana, a partir del momento de la incubación a $37^{\circ} \mathrm{C}$.

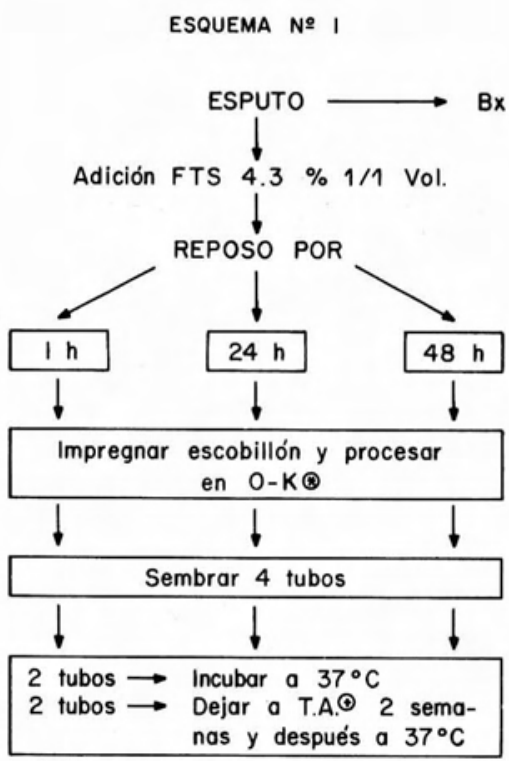

(2) O-K Uno vez impregnado el escobillón se introduce durante 1 a 2 minutos en $\mathrm{NaOH}$ al $4 \%$ y se siembra por roloción y presión en medio de OGAWA modificado por KUDOH.

(1) Temperatura Ambiente $18-25^{\circ} \mathrm{C}$.

* Jefe Grupo de Micobacterias, Instituto Nacional de Salud.

** Bacterióloga Grupo de Micobacterias, Instituto Nacional de Salud.

*** Bacterióloga Sección Control Biológico, Instituto Nacional de Salud. Solicitud reimpresos: Dr. Luis Carlos Orozco, A.A.78091 Bogotá. 
Los cultivos fueron calificados como positivos o negativos y las diferencias evaluadas por la prueba $\mathbf{Q}$ de Cochrane ${ }^{(4)}$; el mismo método fue utilizado para evaluar la contaminación.

\section{RESULTADOS}

La tabla 1 muestra los porcentajes de positividad y contaminación de los cultivos. La positividad osciló entre $25.3 \%$ y $17.4 \%$, a pesar de esta diferencia la prueba $\mathrm{Q}$ de Cochrane $\left(\mathrm{x}^{2}=6.52 \mathrm{P}<0.26\right)$ no nos permite rechazar la hipótesis nula de no diferencia en la positividad del cultivo, en las seis variantes de procesamiento.

La contaminación se presentó entre $10.6 \%$ y $0 \%$ $\left(\mathrm{x}^{2}=18.42 \mathrm{P}<0.005\right)$ lo que permite afirmar que las diferencias en contaminación fueron significativas, disminuyendo progresivamente a medida que aumentó el tiempo de exposición al FTS.

TABLA N2 I

POSITIVIDAD Y CONTAMINACION DE LOS CULTIVOS

\begin{tabular}{|c|c|c|c|c|c|c|c|}
\hline \multirow{2}{*}{\multicolumn{2}{|c|}{$\frac{\text { TIEMPO }}{\text { Incubación }}$}} & \multicolumn{2}{|c|}{ I hora } & \multicolumn{2}{|c|}{24 horas } & \multicolumn{2}{|c|}{48 horas } \\
\hline & & $37^{\circ} \mathrm{C}$ & TA & $37^{\circ} \mathrm{C}$ & TA & $37^{\circ} \mathrm{C}$ & TA \\
\hline \multirow{2}{*}{$\begin{array}{c}\text { Positividad } \\
\text { Cultivos }\end{array}$} & $\mathrm{n}$ & 19 & 14 & 14 & 16 & 15 & 13 \\
\hline & $\%$ & 25.3 & 18.7 & 18.7 & 21.3 & 20.0 & 17.4 \\
\hline \multirow{2}{*}{$\begin{array}{c}\text { Contaming } \\
\text { ción } \\
\text { Cultivos }\end{array}$} & $\mathrm{n}$ & 4 & 8 & 3 & 4 & 0 & 0 \\
\hline & $\%$ & 5.3 & 10.6 & 4.0 & 5.3 & 0 & 0 \\
\hline
\end{tabular}

\section{DISCUSION}

La atención primaria en salud pretende que tanto la prevención como el diagnóstico y el tratamiento de los problemas más importantes de salud de la comunidad puedan ser realizados con recursos mínimos sin mayor desplazamiento del paciente ${ }^{(5)}$.

Aunque el método del escobillón en medio de O-K ha simplificado el procesamiento de la muestra de esputo para el diagnóstico etiológico de la tuberculosis por cultivo e identificación del agente causal y por lo tanto el cultivo como procedimiento de diagnóstico se ha podido extender a aquellos lugares donde existe una incubadora microbiológica, aún no se había evaluado la posibilidad de las siembras en lugares donde no existe dicho recurso, para un posterior envío a un lugar donde existiera incubadora.

Nuestro trabajo anterior ${ }^{(3)}$ nos alentó a dicha posibilidad, la cual fue confirmada en el presente trabajo.

Las aparentes diferencias de positividad no son más que un fenómeno del azar dado por la división de las muestras en 6 alícuotas; por el contrario la contaminación disminuyó en relación inversa al tiempo de exposición al FTS, en forma significativa.

Por todo lo anterior, creemos que el cultivo de esputo para el diagnóstico etiológico de la tuberculosis se podrá practicar en cualquier lugar, donde una persona con muy poco entrenamiento, mezcle el esputo con FTS al $4.3 \%$ y después de 24 horas de realizada la mezcla, practique la siembra por el método del escobillón en medio de $\mathrm{O}-\mathrm{K}^{(1)}$ y pueda esperar hasta dos semanas para su envío a un laboratorio donde exista el recurso de la incubación microbiológica.

\section{BIBLIOGRAFIA}

1. Orozco LC, León Cl, Blanco E de, Ramos $\mathrm{O}$ de, Moreno Al de. El cultivo de esputo para el diagnóstico de tuberculosis pulmonar. Biomédica 1985; 5: 3 y 4. 24-25.

2. Orozco LC, León Cl, Blanco E de, Ramos O de, Moreno Al de. Una modificación al método de Kudoh para el cultivo de M. tuberculosis. Biomédica 1985; 5 : 3 y 4, 86-89.

3. Esper E, Orozco LC. Viabilidad del M. tuberculosis expuesto al FTS en medio de O-K a temperatura ambiente. Biomédica 1983; 3: 1 y 2, 22-25.

4. Sokal RR, Rohlf FJ. Biometry WH. Freemand and Co. 1981; pp 770-774.

5. Programa general de trabajo para el período 1984-1989. Ginebra OMS 1982; pp 112-113 (Serie salud para todos No. 8). 